\title{
COMPARATIVE STUDY OF PALISADE CARTILAGE TYMPANOPLASTY WITH TEMPORALIS FASCIA TYMPANOPLASTY IN CSOM WITH SUBTOTAL PERFORATIONS
}

\author{
Sathish Kumar K. N1, M. K. Veenapani², Swathi V. M³
}

${ }_{1}^{1}$ Assistant Professor, Department of ENT, MMCRI, Mysuru, Karnataka, India.

${ }^{2}$ Professor, Department of ENT, MMCRI, Mysuru, Karnataka, India.

${ }^{3}$ Audiologist, Department of ENT, MMCRI, Mysuru, Karnataka, India.

ABSTRACT
BACKGROUND
CSOM is a very common cause of deafness in India. Tubotympanic type of CSOM is characterised by a permanent perforation in
the tympanic membrane, which needs surgical closure by a graft material.
The aim of this study is to assess and compare the graft acceptance rates and audiological outcomes of palisade cartilage
tympanoplasty with those of temporalis fascia tympanoplasty in CSOM with subtotal perforation.

\section{MATERIALS AND METHODS}

A non-randomised controlled trial containing 50 patients with the diagnosis of CSOM with subtotal perforations attending the Department of ENT, KR Hospital between January 2017 and December 2017. Patients were divided into two groups with equal number of patients in each group. Detailed history and clinical examination along with PTA (Pure Tone Audiometry) was performed. Pre- and post-operative graft success results and hearing improvement results were assessed and compared.

\section{RESULTS}

Significant hearing improvement was seen in both types of surgeries. Graft success rates and hearing results were slightly better in temporalis fascia tympanoplasty than cartilage tympanoplasty, but the difference was not statistically significant.

\section{CONCLUSION}

Tympanoplasty is the surgical procedure done for the management of CSOM with subtotal perforation. Both temporalis fascia and cartilage are excellent graft materials for closure of perforations and hearing improvement. But there was no statistically significant difference in surgical success rate and hearing gain between the two groups.

\section{KEY WORDS}

Tympanoplasty, Temporalis Fascia, Cartilage, Palisade, Subtotal Perforation.

HOW TO CITE THIS ARTICLE: Kumar SKN, Veenapani MK, Swathi VM. Comparative study of palisade cartilage tympanoplasty with temporalis fascia tympanoplasty in CSOM with subtotal perforations. J. Evolution Med. Dent. Sci. 2018;7(34):3739-3743, DOI: $10.14260 /$ jemds/2018/840

\section{BACKGROUND}

Tubotympanic type of CSOM (Chronic Suppurative Otitis Media) is a chronic inflammatory condition of the middle ear characterised by a perforation in the pars tensa of tympanic membrane. When the perforation involves all the 4 quadrants of pars tensa, it is called as subtotal perforation. Tympanoplasty is the surgery done for the management of CSOM with subtotal perforation.

The aims of tympanoplasty are elimination of disease and restoration of function by closure of tympanic membrane perforation and reconstruction of ossicular chain defect if present. Various graft materials have been used for closure of perforation including temporalis fascia, fat, vein, dura and cartilage. But the most frequently used graft material is temporalis fascia. More recently, the use of cartilage has been increasingly described for the

'Financial or Other Competing Interest': None.

Submission 26-07-2018, Peer Review 08-08-2018,

Acceptance 10-08-2018, Published 18-08-2018.

Corresponding Author:

Dr. Sathish Kumar K. N

\#C-178, Panchavati,

$5^{\text {th }}$ Cross, Adarsha Nagar,

Hassan-573201, Karnataka, India.

E-mail: sathishronann@yahoo.com

DOI: $10.14260 /$ jemds $/ 2018 / 840$

(c) $(1)$ reconstruction of large portions of pars tensa of the tympanic membrane and also in atelectatic ears and revision surgery.

In the palisade technique of cartilage tympanoplasty, the tympanic membrane is fully reconstructed with palisadeshaped cartilage pieces. The rigidity and stiffness of the cartilage provide better mechanical stability under negative pressure changes in the middle ear. However, there have been concerns that the same properties of cartilage graft may adversely affect acoustic transfer and lead to increased acoustic impedance.

The aim of the present study was to compare the graft success rates and audiological outcomes of palisade cartilage tympanoplasty with those of temporalis fascia tympanoplasty.

\section{MATERIALS AND METHODS}

This is a non-randomised controlled trial carried out over a period of one year from January 2017 to December 2017 at KR Hospital, Mysuru. The study included 50 patients suffering from CSOM with subtotal perforations. They were divided into 2 groups with equal number of patients in each group (25 patients in each group). Group A underwent tympanoplasty with cartilage graft and Group B underwent tympanoplasty with temporalis fascia graft. 


\section{Sample Size}

It was a time-bound study and based on the statistics of previous year (2016) the number of tympanoplasties done was approximately 60 cases.

\section{Inclusion Criteria}

- Tubotympanic type of CSOM with subtotal perforation (perforation involving all the four quadrants of pars tensa).

- Dry ear for at least 6 weeks.

- Patent eustachian tube.

- Patients in the age group of 16 - 60 years.

\section{Exclusion Criteria}

- Previous history of ear surgery.

- Associated sensorineural hearing loss, external ear infections and ossicular defect.

\section{Statistical Analysis}

Data was entered into Microsoft Excel data sheet and was analysed using SPSS 22 version (IBM SPSS Statistics, Somers NY, USA) software. Categorical data was represented in the form of frequencies and proportions. Chi-square test was used as test of significance for qualitative data. Continuous data was represented as mean and standard deviation. Independent t-test was used as test of significance to identify the mean difference between two quantitative variables. Paired t-test is the test of significance for paired data such as before and after surgery for quantitative data. P-value (Probability that the result is true) of $<0.05$ was considered as statistically significant after assuming all the rules of statistical tests.

\section{Method of Collection of Data}

All the cases were subjected to detailed history and clinical examination. Examination under microscope was performed for all the cases to confirm the diagnosis. Pure tone audiometry was performed and air conduction threshold and air-bone gap were noted.

Patients were divided into 2 groups. Group A patients underwent tympanoplasty with cartilage graft and Group B patients underwent tympanoplasty with temporalis fascia graft. Both tympanoplasty techniques were performed under general anaesthesia by postaural approach.

In Group A patients who underwent Cartilage tympanoplasty, graft was taken from conchal cartilage, cut into several slices that are subsequently pieced together, similar to a jigsaw puzzle to reconstruct the tympanic membrane. Perichondrium was removed from the posterior side of conchal cartilage. The convex side of the palisade was turned towards the tympanic cavity and was not covered with perichondrium. The cartilage was cut into $0.5-3 \mathrm{~mm}$ wide strips. The palisades were placed in an over-under fashion (two placed anterior to the malleus handle and 2 to 3 placed posteriorly). Gelfoam was placed both medial and lateral to the graft.

In Group B patients who underwent temporalis fascia tympanoplasty, graft was taken from the fascia covering the temporalis muscle. Graft was placed by underlay technique and gel foam was placed both medial and lateral to the graft.

Post-operatively, patients were given IV antibiotics. Patients were discharged on the first post-operative day and were given oral antibiotics in the form of co-amoxiclav twice a day with oral decongestants (Phenylephrine $10 \mathrm{mg}$ ) once daily for one week. Sutures were removed after 7 days.

Regular follow-up was done once a month upto 3 months. At the end of 3 months, otomicroscopic examination was done to look for acceptance of graft (Graft success) and pure tone audiometry was done to evaluate and compare the hearing results between the two groups.

Patient's data were reviewed for changes in the preoperative and post-operative Air-Bone Gap (ABG) and changes in the pre-operative and post-operative air conduction threshold. Air conduction threshold is the mean of four pure tone averages $(500 \mathrm{~Hz}, 1 \mathrm{kHz}, 2 \mathrm{kHz}, 4 \mathrm{kHz})$.

\section{RESULTS}

The present study included 50 patients with the diagnosis of CSOM with subtotal perforation. They were divided into 2 groups with 25 patients in each group.

In Group A $20 \%$ were in the age group < 20 years, $36 \%$ were in the age group 21 to 30 years and 31 to 40 years respectively and $8 \%$ were in the age group $>40$ years.

In Group B 28\% were in the age group < 20 years, 32\% were in the age group 21 to 30 years, $28 \%$ were in the age group 31 to 40 years and $12 \%$ were in the age group $>40$ years.

Mean ages for Group A and Group B were 28.37+/- 7.910 and $29.40+/-10.235$ respectively.

Group A had 12 females (48\%) and 13 males (52\%). Group B had 15 females (60\%) and 10 males (40\%).

Left CSOM was present in 25 patients divided into 11 patients (44\%) in Group A and 14 patients (56\%) in Group B.

Right CSOM was present in 25 patients (50\%), divided into 14 patients (56\%) in Group A and 11 patients (44\%) in Group B.

There was no significant difference in Age, Sex distribution and diagnosis between two groups.

\begin{tabular}{|c|c|c|c|c|c|c|}
\hline & \multicolumn{4}{|c|}{ Group } & \multirow{3}{*}{$\begin{array}{c}P \\
\text { value }\end{array}$} \\
\hline & & \multicolumn{2}{|c|}{ Group A } & \multicolumn{2}{|c|}{ Group B } & \\
\hline & & \begin{tabular}{|l|} 
Count \\
\end{tabular} & $\%$ & Count & $\%$ & \\
\hline \multirow{5}{*}{ Age } & $<20$ years & 5 & $20.0 \%$ & \begin{tabular}{|l|}
7 \\
\end{tabular} & $28.0 \%$ & \multirow{5}{*}{0.839} \\
\hline & $\begin{array}{c}21 \text { to } 30 \\
\text { years }\end{array}$ & 9 & $36.0 \%$ & 8 & $32.0 \%$ & \\
\hline & $\begin{array}{c}31 \text { to } 40 \\
\text { years }\end{array}$ & 9 & $36.0 \%$ & 7 & $28.0 \%$ & \\
\hline & $>40$ years & 2 & $8.0 \%$ & 3 & $12.0 \%$ & \\
\hline & Mean \pm SD & \multicolumn{2}{|c|}{$28.36 \pm 7.910$} & \multicolumn{2}{|c|}{$29.40 \pm 10.235$} & \\
\hline \multirow{2}{*}{ Sex } & \begin{tabular}{|l|} 
Female \\
\end{tabular} & 12 & $48.0 \%$ & \begin{tabular}{|l|l|}
15 \\
\end{tabular} & $60.0 \%$ & \multirow{2}{*}{0.395} \\
\hline & Male & 13 & $52.0 \%$ & 10 & $40.0 \%$ & \\
\hline \multirow[b]{2}{*}{ Diagnosis } & Left CSOM & 11 & $44.0 \%$ & 14 & $56.0 \%$ & \multirow[b]{2}{*}{0.396} \\
\hline & $\begin{array}{l}\text { Right } \\
\text { CSOM }\end{array}$ & 14 & $56.0 \%$ & 11 & $44.0 \%$ & \\
\hline & & Ibject & $\begin{array}{l}\text { ts comp } \\
\text { oups }\end{array}$ & & & \\
\hline
\end{tabular}

\section{Audiological Results}

Pure tone audiometry was done pre-operatively and also at the end of 3 months. Pre- and Post-operative Air-Bone Gap and pre- and post-operative air conduction threshold was measured and compared between the two groups. 


\section{AC Comparison}

In Group A pre-operative AC (Air Conduction Threshold) was $37.66+/-1.10$ and post-operative AC (Air Conduction Threshold) was $17.61+/-7.01$. There was significant decrease (improvement) in AC in Group A after the surgery.
In Group B pre-operative AC (air conduction threshold) was $38.40+/-1.33$ and post-operative AC (air conduction threshold) was $17.10+/-5.74$. There was significant decrease (improvement) in AC in Group B after the surgery.

\begin{tabular}{|c|c|c|c|c|c|c|c|c|c|}
\hline & \multicolumn{8}{|c|}{ Group } & \multirow{3}{*}{$\begin{array}{c}\text { P value } \\
\text { b/w Two } \\
\text { Groups }\end{array}$} \\
\hline & \multicolumn{4}{|c|}{ Group A } & \multicolumn{4}{|c|}{ Group B } & \\
\hline & Mean & SD & Median & $\begin{array}{c}\text { P value } \\
\text { within } \\
\text { Group A }\end{array}$ & Mean & SD & Median & $\begin{array}{l}\text { P Value } \\
\text { within } \\
\text { Group B }\end{array}$ & \\
\hline $\begin{array}{c}\text { Pre-op PTA AC } \\
\text { Threshold Mean }\end{array}$ & 37.66 & 1.10 & 37.50 & & 38.40 & 1.33 & 38.75 & & 0.036 \\
\hline $\begin{array}{l}\text { Post-op PTA AC } \\
\text { Threshold Mean }\end{array}$ & 17.61 & 7.01 & 15.00 & $<0.001^{*}$ & 17.10 & 5.74 & 15.00 & $<0.001^{*}$ & 0.780 \\
\hline
\end{tabular}

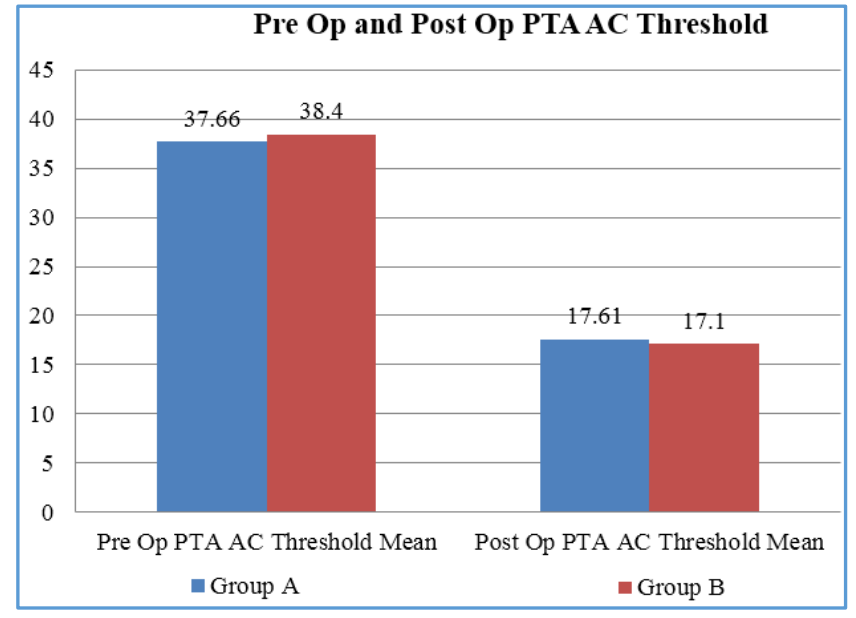

Figure 1. Bar Diagram showing Pre-op and Post-op AC threshold comparison between Two Groups

\section{ABG Comparison}

In Group A, pre-operative ABG was $29.73+/-1.77$ and postoperative $A B G$ was $13.53+/-5.96$. There was significant decrease (improvement) in ABG in Group A after surgery.

In Group B, pre-operative ABG was $30.30+/-1.99$ and post-op ABG was $10.95+/-4.05$. There was significant decrease (improvement) in ABG in Group B after surgery.

However, there was no significant difference in mean pre-op ABG and post-op ABG between Group A and Group B.

\begin{tabular}{|c|c|c|c|c|c|c|c|c|c|}
\hline & \multicolumn{8}{|c|}{ Group } & \multirow[b]{3}{*}{ P value } \\
\hline & \multicolumn{4}{|c|}{ Group A } & \multicolumn{4}{|c|}{ Group B } & \\
\hline & Mean & SD & Median & $\begin{array}{c}\text { P value } \\
\text { within Group } \\
\text { A }\end{array}$ & Mean & SD & Median & $\begin{array}{c}\text { P value } \\
\text { within Group } \\
\text { B }\end{array}$ & \\
\hline $\begin{array}{c}\text { Pre-op } \\
\text { ABG }\end{array}$ & 29.73 & 1.77 & 30.00 & & 30.30 & 1.99 & 30.00 & & 0.289 \\
\hline $\begin{array}{c}\text { Post-op } \\
\text { ABG }\end{array}$ & 13.53 & 5.96 & 11.25 & $<0.001^{*}$ & 10.95 & 4.05 & 10.00 & $<0.001^{*}$ & 0.080 \\
\hline
\end{tabular}

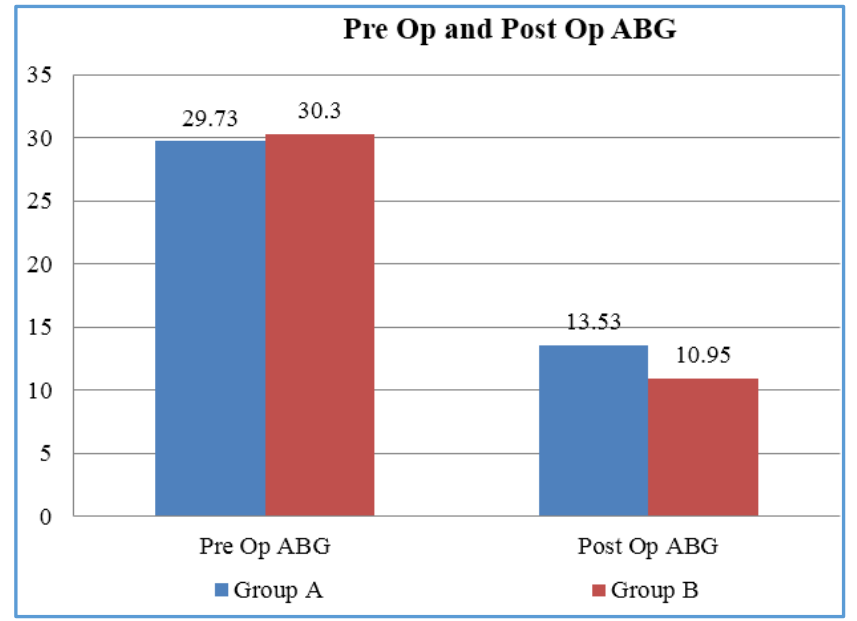

Figure 2. Bar Diagram showing pre-op and post-op ABG comparison between Two Groups

\section{Graft Success Comparison}

In Group A 92\% had success and 8\% had failure and in Group B 96\% had success and 4\% had failure. There was no significant difference in graft success rates between two groups.

\begin{tabular}{|c|c|c|c|c|c|c|}
\hline \multicolumn{2}{|c|}{} & \multicolumn{4}{|c|}{ Group } & \multirow{2}{*}{ P } \\
\cline { 3 - 6 } \multicolumn{2}{|c|}{} & \multicolumn{2}{|c|}{ Group A } & \multicolumn{2}{c|}{ Group B } & value \\
\cline { 3 - 6 } \multicolumn{2}{|c|}{} & Count & \% & Count & \% & \\
\hline $\begin{array}{c}\text { Post-op } \\
\text { Graft } \\
\text { Take-Up }\end{array}$ & Failure & 2 & $8.0 \%$ & 1 & $4.0 \%$ & \\
\cline { 2 - 6 } & Success & 23 & $92.0 \%$ & 24 & $96.0 \%$ & 0.552 \\
\hline
\end{tabular}

Table 4. Outcome comparison between Two Groups 


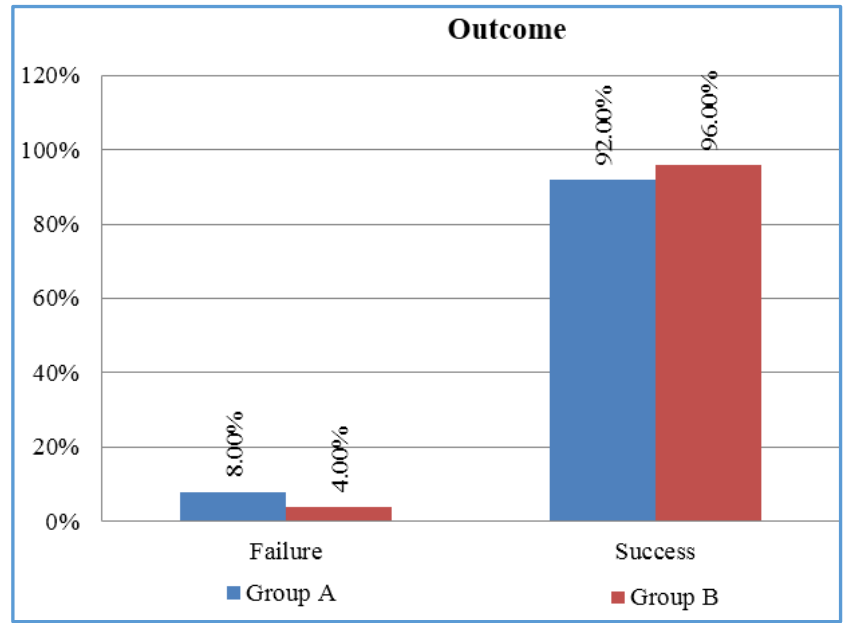

Figure 3. Bar Diagram showing graft success comparison between Two Groups

\begin{tabular}{|c|c|c|c|c|c|}
\hline & 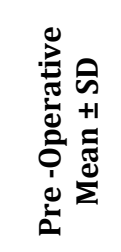 & 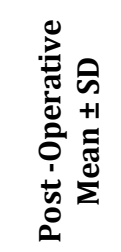 & 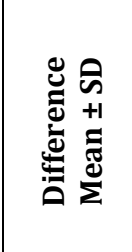 & $\begin{array}{l}\frac{0}{2} \\
\frac{\pi}{2} \\
2\end{array}$ & 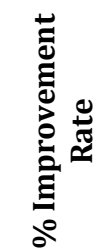 \\
\hline \multicolumn{6}{|c|}{ Group A } \\
\hline $\mathrm{ABG}$ & $\begin{array}{c}29.73 \pm \\
1.77\end{array}$ & $\begin{array}{c}13.53 \pm \\
5.96\end{array}$ & $\begin{array}{c}16.204 \pm \\
5.90\end{array}$ & $<0.001^{*}$ & $\begin{array}{c}54.5 \pm \\
19.2\end{array}$ \\
\hline $\mathrm{AC}$ & $\begin{array}{c}37.66 \pm \\
1.10\end{array}$ & $\begin{array}{c}17.61 \pm \\
7.01\end{array}$ & $\begin{array}{c}20.046 \pm \\
6.80\end{array}$ & $<0.001^{*}$ & $\begin{array}{c}53.3 \pm \\
17.8\end{array}$ \\
\hline \multicolumn{6}{|c|}{ Group B } \\
\hline $\mathrm{ABG}$ & $\begin{array}{c}30.30 \pm \\
1.99\end{array}$ & $\begin{array}{c}10.95 \pm \\
4.05\end{array}$ & $\begin{array}{c}19.350 \pm \\
4.56\end{array}$ & $<0.001^{*}$ & $\begin{array}{c}63.6 \pm \\
13.7\end{array}$ \\
\hline $\mathrm{AC}$ & $\begin{array}{c}38.40 \pm \\
1.33\end{array}$ & $\begin{array}{c}17.10 \pm \\
5.74\end{array}$ & $\begin{array}{c}21.300 \pm \\
5.56\end{array}$ & $<0.001^{*}$ & $\begin{array}{c}55.5 \pm \\
14.4\end{array}$ \\
\hline
\end{tabular}

In the present study, there was significant difference in mean difference of $\mathrm{ABG}$ and $\mathrm{AC}$ between pre-operative and post-operative values in both Group A and Group B.

\section{DISCUSSION}

The use of cartilage in the middle ear surgery is not a new concept. It has been advocated to manage retraction pockets and in adhesive otitis media. But it was not a popular graft material for repair of pars tensa perforation.

Because of its rigid and stiff nature, cartilage has the advantage of providing good anatomical results preventing retraction. But many argue that it may alter the acoustic transfer characteristics of the graft due to the increasing mass and stiffness of the reconstructed tympanic membrane.

This study was therefore conducted to assess not only the anatomical results, but also functional results of tympanoplasty with cartilage graft in terms of hearing improvement and compare the results with those of tympanoplasty with temporalis fascia graft.

There was no significant difference in age, sex distribution and diagnosis between two groups.

In the present study, graft survival rates were $92 \%$ in Group A (Cartilage graft) and 96\% in Group B (Temporalis fascia graft). The difference in outcome between the two groups was not statistically significant.
Our results are comparable to other studies. For example, in a study conducted by Gamra et al, graft success rate was $97.7 \%$ with cartilage graft and $96.9 \%$ with fascia graft. ${ }^{1}$ In the study conducted by Ulko, graft success rate was $91.3 \%$ with cartilage graft and $88.2 \%$ with fascia graft. ${ }^{2}$ In the study conducted by Mauri et al, graft success rate was $88.2 \%$ with cartilage graft and $86.1 \%$ with fascia graft. ${ }^{3}$

In the present study, significant hearing improvement was seen in both groups after surgery in terms of changes in AC (Air conduction threshold) and ABG (Air-bone gap). Preop AC was $37.66+/-1.10$ and post-op AC was $17.61+/-7.01$ in Group A with significant improvement. Pre-op AC was $38.40+/-1.33$ and post-op AC was $17.10+/-5.74$ in Group B with significant hearing improvement. But the difference between two groups was not statistically significant.

In Group A, pre-op ABG was 29.73 +/- 1.77 and post-op ABG was $13.53+/-5.96$ with significant improvement.

In Group B, pre-op ABG was $30.30+/-1.99$ and post-op ABG was $10.95+/-4.05$ with significant improvement.

However, there was no statistically significant difference between two groups.

Our study results match with other studies. In 2004, Gierek et al conducted a study with 112 cartilage graft and 30 fascia grafts and observed that there was no significant difference in hearing improvement between two groups. 4

Couloigner et al compared 59 cartilage tympanoplasty cases with 29 temporalis fascia tympanoplasty cases and found no significant difference between the two techniques in terms of hearing improvement. ${ }^{5}$

Kazikdas et al performed 23 cartilage tympanoplasty cases and 28 temporalis fascia tympanoplasty cases and found no significant difference between the two techniques in terms of hearing improvement. 6

Generally, cartilage is used as a graft material in case of atelectatic ears, high risk perforation and cholesteatoma. High risk perforation includes a perforation larger than 50\% of pars tensa, perforation anterior to the annulus, revision surgery and discharging ear at the time of surgery. It was not a popular technique for the management of perforation in pars tensa because of its thickness and rigidity, which may affect adversely acoustic transfer and the hearing.

But several recent studies have reported results to the contrary, suggesting hearing results with cartilage graft for pars tensa perforations to be no different than results with fascia graft. It has been shown that cartilage is well tolerated by the middle ear, and long-term survival is the norm. Cartilage graft is nourished by diffusion and becomes well incorporated in the tympanic membrane. Some softening may occur with time, but the matrix of the cartilage remains intact. Cartilage also offers high resistance both to infections and lack of vascularity.

Our study showed that conchal cartilage is not only an excellent graft material for management of CSOM with subtotal perforation, but also equally good in achieving good hearing results which are comparable to temporalis fascia graft technique.

\section{CONCLUSION}

Tympanoplasty with temporalis fascia graft is a widely practiced surgery for the management of CSOM with subtotal perforation with excellent results in terms of graft acceptance rates and hearing improvement. On the basis of 


\section{Jemds.com}

the results of the present study, cartilage graft can be safely used for CSOM with subtotal perforation with equally good surgical and audiological results.

\section{REFERENCES}

[1] Gamra OB, Mbarek C, Khammasi K, et al. Cartilage graft in type 1 tympanoplasty: audio logical and otological outcome. Eur Arch Otorhinolaryngol 2008;265(7):739-42.

[2] Ulku CH. Cartilage tympanoplasty with island technique for reconstruction of tympanic membrane perforation: anatomic and audiological results. Kulak Burun Bogaz Ihtis Derg 2010;20(1):7-12.

\section{Original Research Article}

[3] Mauri M, Neto JFL, Fuchs SC. Evaluation of inlay butterfly cartilage tympanoplasty: a randomised clinical trial. Laryngoscope 2001;111(8):1479-85.

[4] Gierek T, Slaska-Kaspera A, Majzel K, et al. Results of myringoplasty and type 1 tympanoplasty with the use of fascia, cartilage and perichondrium grafts. Otolaryngologia Polska 2004;58(3):529-33.

[5] Couloigner V, Baculard F, El Bakkouri W, et al. Inlay butterfly cartilage tympanoplasty in children. Otol \& Neurotol 2005;26(2):247-51.

[6] Kazikdas KC, Onal K, Boyraz I, et al. Palisade cartilage tympanoplasty for management of subtotal perforations: a comparison with the temporalis fascia technique. Eur Arch Otorhinolaryngol 2007;264(9):985-9. 